\title{
The long-awaited first instar larva of Paussus favieri (Coleoptera: Carabidae: Paussini)
}

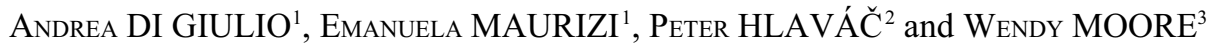 \\ ${ }^{1}$ Dipartimento di Biologia Ambientale, Università degli Studi "Roma Tre”, Viale G. Marconi 446, I-00146 Roma, Italy; \\ e-mails: digiulio@uniroma3.it; emaurizi@uniroma3.it \\ ${ }^{2} \mathrm{Na}$ doline 14, 04014 Košice, Slovakia; e-mail: phlavac@stonline.sk \\ ${ }^{3}$ Department of Entomology, University of Arizona, Tucson, Arizona 85721-0036, USA; e-mail: wmoore@email.arizona.edu
}

Key words. Carabidae, Paussini, flanged bombardier beetles, Paussus favieri, first instar larva, taxonomy, functional morphology, myrmecophily, Formicidae, Pheidole pallidula

\begin{abstract}
Paussus favieri Fairmaire is one of only two species of the myrmecophilous carabid tribe Paussini known from Europe. Larvae are known from only 10 of the 580 paussine species. As in many beetles with considerably modified later instar larvae, the first instars represent a valuable source of informative characters for taxonomy and phylogenetic analyses (primary chaetotaxy, eggbursters, etc.). Therefore, the discovery of the first instar larva of $P$. favieri is particularly important, as it represents only the second species for which this larval stage is known. In this paper we describe the behavior and morphology of the larval first instar of $P$. favieri (subtribe Paussina of Paussini) and compare it with that of Arthropterus sp. (subtribe Cerapterina), which is the only other 1st instar described in the Paussini. Most surprisingly, we found that the 1st instar of $P$. favieri lacks a prostheca, which was previously thought to be a synapomorphy of Paussina + Platyrhopalina. Rather, P. favieri has a unique mandibular structure that seems to be functionally analogous to the protheca. It is a long, broadly lanceolate, distinctly flattened structure apparently homologous to the medial mandibular seta $(\mathrm{MN} 2 *)$, which arises from an area behind the cutting edge of mandible. We predict that the function of the protheca and this similar structure in P. favieri are involved in a specialized feeding strategy that may include soliciting trophallaxis from their host ants. We also report some observations of the first instar hatching from the egg, feeding on liquid and a behaviour we interpret as a "calling behavior," all of which were videotaped and posted on the Tree of Life Web Project.
\end{abstract}

\section{INTRODUCTION}

Myrmecophiles (obligate symbionts of ants) are challenging to study because they are rare, they live in concealed environments (ant nests), and they have complex but little understood interactions with their hosts. While it is difficult to study their behavior and life cycle in nature, there are also challenges rearing them in laboratory conditions. Because these difficulties hamper direct observations, the nature of most interactions between myrmecophiles and ants, and the function of many structural adaptations, remain a mystery or a matter of speculation (e.g., Di Giulio \& Moore, 2004).

Myrmecophiles possess specialized adaptations in order to be accepted by ants and to survive and develop within their nests. Such adaptations include: chemical and morphological mimicry; specialized behaviors to feed on and/or be fed by ants; and structural and chemical modifications to avoid ant attacks. Holometabolous myrmecophiles are unique in that they have different suites of adaptations for very different life history stages (larva, pupa, adult). For many holometabolous myrmecophiles, adults can freely enter and leave the nests, but the larvae (and pupae) must remain in the nest full-time and they are completely dependent upon the ants for survival.

Most members of the carabid beetle subfamily Paussinae are myrmecophiles and all members of this subfamily have a unique type of larva referred to as "dis- cotelic" (Di Giulio, 1999, 2008) for the presence of a wide, transverse, plate-like structure, called the terminal disk at the end of an up-curved abdomen (Bousquet, 1986; Di Giulio, 1999; Di Giulio et al., 2000). The terminal disk is composed of modified epipleurites VIII and IX, tergite VIII, and the urogomphi. In free-living, nonmyrmecophilous larvae the terminal disk is used to trap prey through an ambush feeding strategy, after the prey are attracted to it by chemical attractants (Costa et al., 1988; Di Giulio, 1999; Di Giulio \& Vigna Taglianti, 2001; Moore \& Di Giulio, 2006). All described species of the monophyletic tribe Paussini are thought to be parasitic myrmecophiles as both larvae and adults (Darlington, 1950; Nagel, 1979, 1997; Di Giulio \& Moore, 2004; Geiselhardt et al., 2007). Components of the terminal disk are fused in myrmecophilous Paussini larvae such that they cannot trap prey like their free-living relatives. Substances on the fused terminal disk most likely appease ants and play important roles in establishing and maintaining of their symbiosis with ants (Bøving, 1907; Oberprieler, 1985; Bousquet, 1986; Luna de Carvalho, 1989; Di Giulio \& Moore, 2004; Di Giulio, 2008).

The first Paussini larva was discovered more than hundred years ago (Bøving, 1907; Di Giulio, 2008). Since then our knowledge of the group has grown very slowly. To date, we know larvae of only 10 of approximately 580 described species (for a list, see Di Giulio \& Moore, 
2004; Di Giulio, 2008; Nagel, 2009), representative of 3 of the 7 subtribes (Cerapterina, Platyrhopalina, Paussina) and 4 of the 22 genera (Arthropterus W.S. MacLeay, 1838, Platyrhopalopsis Desneux, 1905, Paussus Linnaeus, 1775, Granulopaussus Kolbe, 1938). Two other larval descriptions (Wasmann, 1918; Brauns, 1914; van Emden, 1922) are too vague and superficial to be useful, the identifications having been based solely upon speculations, and the deposition of material is unknown ( $\mathrm{Di}$ Giulio et al., 2003; Di Giulio \& Moore, 2004; Di Giulio, 2008). While first instar larvae are widely acknowledged to be an important source of diagnostic characters (i.e., primary chaetotaxy and egg burster shape) (Bousquet \& Goulet, 1984), most of the described Paussini larvae are second or third instars. To date the only first instar larva described in this tribe is that of Arthropterus sp., classified in the subtribe Cerapterina (Di Giulio \& Moore, 2004).

The tribe Paussini is mainly tropical and subtropical with very few species known in the Palearctic Region (see Nagel, 2003 for an updated list). Only two species are distributed in Europe, Paussus turcicus I. Frivaldszky von Frivald, 1835 and P. favieri Fairmaire, 1851. Paussus turcicus occurs in West-Balcan, Turkey, S-Caucasus and Turkmenistan (Nagel, 1987, 2003) and P. favieri is an Atlanto-Mediterranean species (Nagel, 1987, 2003) present in southwestern France, Spain, Portugal, Morocco, Algeria and Tunisia (Casale et al., 1982; Nagel, 1987). There are some museum specimens of $P$. favieri from Sicily and Sardinia (Casale et al., 1982), and one from Corsica (Zerche, 1990), however, no specimens have been collected on these islands during the past 100 years. The closest relatives of $P$. favieri, are $P$. biflagellatus Luna de Carvalho, 1973 and P. krelli Kaupp \& Rödel, 1997 (Luna de Carvalho, 1980; Kaupp \& Rödel, 1997) known only from the sub-Saharan countries of Ghana and the Ivory Coast. For over 150 years $P$. favieri has attracted the intense interest of researchers and collectors, due to its rarity, its bizarre structural adaptations to a myrmecophilous lifestyle, and the fact that it is one of the few paussine species known from the Mediterranean Region. Through the years, many researchers have tried to learn about the life cycle and preimaginal stages of this species but to no avail (an apodous, physogastric larva was erroneously attributed to $P$. favieri by Xambeu, 1892).

Recently, on a collecting expedition to the High Atlas Mountains of Morocco we collected a gravid female of $P$. favieri and in our laboratory in Rome we were able to rear the first instar larva of this remarkable species. These specimens represent the first record ever of first instar specimens of the subtribe Paussina. In this paper we describe $P$. favieri first instar larval morphology, provide notes on collecting adults, rearing conditions and behavior of the larva in captivity. We also compare this larva to the first instar of Arthropterus, the only other first instar described for the tribe Paussini.

\section{MATERIAL AND METHODS}

Several adult specimens of Paussus favieri, collected during an expedition to High Atlas Mountains in Morocco (2009) from

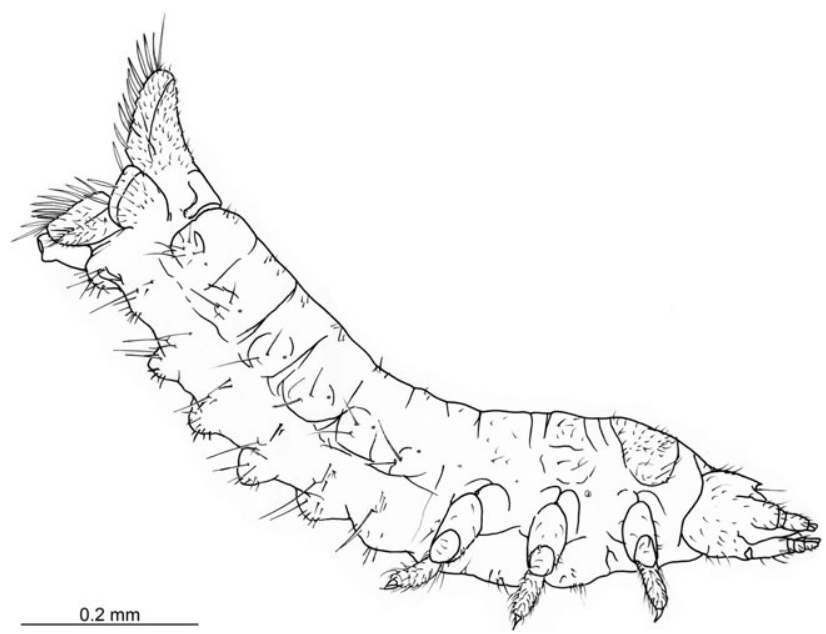

Fig. 1. Paussus favieri first instar larva, right lateral view.

nests of Pheidole pallidula (Nylander, 1849), were kept in captivity for about one month under controlled conditions. During this time, their behavior and interactions with their host ants were studied (Di Giulio et al., unpubl.). One of the females laid two eggs on the moist filter paper. Eggs were held at room temperature (about $25^{\circ} \mathrm{C}$ ), inside a vial closed by a moist cotton plug. Two larvae hatched eleven days after isolation. Larvae were observed under Olympus SZX16 stereomicroscope, and interactions among the larvae, adults and host ant brood were recorded by a camera (ColorView II, AnalySIS software Olympus SIS, Cell $* \mathrm{D}, 2006$ ). Two days after hatching, the small larvae were submerged in boiling distilled water for a few seconds and then transferred to $70 \% \mathrm{EtOH}$. Larvae were drawn using Olympus SZX16 equipped with drawing tube (Figs 1-5). Then, one specimen was rehydrated, cleared in $10 \% \mathrm{KOH}$, transferred to hot lactic acid, dehydrated through a series of EtOH baths of increasing concentration (10, 20, 50, 70, 90, 95 and $100 \%$ ), left overnight in a clove oil bath, and mounted on a slide with Canada balsam. This specimen was illustrated by using a light microscope Olympus BX51 equipped with drawing tube. The second specimen was dehydrated through a series of EtOH baths of increasing concentration $(70,80,90,95$ and $100 \%$ ), critical point dried (Bal-Tec CPD 030), mounted on a stub (by using self adhesive carbon disks), sputtered with gold (Emitech k550 sputter coater), and observed with Philips XL30 scanning electron microscope and FEI Dualbeam FIB/SEM Helios Nanolab (L.I.M.E. laboratory, University "Roma Tre", Rome). In this paper, the general terminology of larval structures follows Lawrence (1991). The term "frontoclypeolabrale" is used here instead of "frontale" or "frontal plate" (more often used in larval taxonomy of Carabidae) or "frons" or "frontoclypeal region" (see Lawrence, 1991), following the recent taxonomic descriptions of Paussinae (Di Giulio \& Moore, 2004, 2009; Moore \& Di Giulio, 2006) and the available larval key (http://tolweb.org/notes/?note_id=3430). Notation of primary setae and pores follows the system of Bousquet \& Goulet (1984), modified for Metrius contractus Eschscholtz, 1829 (Bousquet, 1986). As some of the sensilla of $P$. favieri larva present on the abdomen and terminal disk are homologous to those recognized by Bousquet (1986) in Metrius contractus (sensilla S-I to S-V), by Di Giulio (1999) and Di Giulio et al. (2000) in several species of Pachyteles Perty, 1830 (sensilla S-I to S-VII), and by Di Giulio \& Moore (2004) in Arthropterus sp. (sensilla S-I to S-VIII), we adopted the same nomenclature used by these authors. Notation of microsculpture follows Harris (1979). An asterisk $(*)$ following a coded seta indicates that the homology 


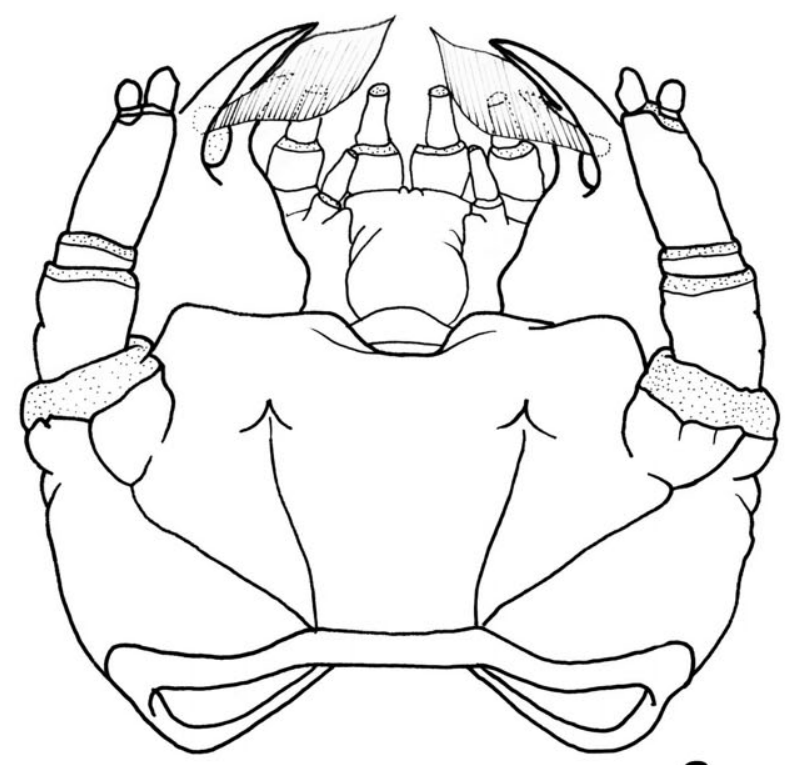

a

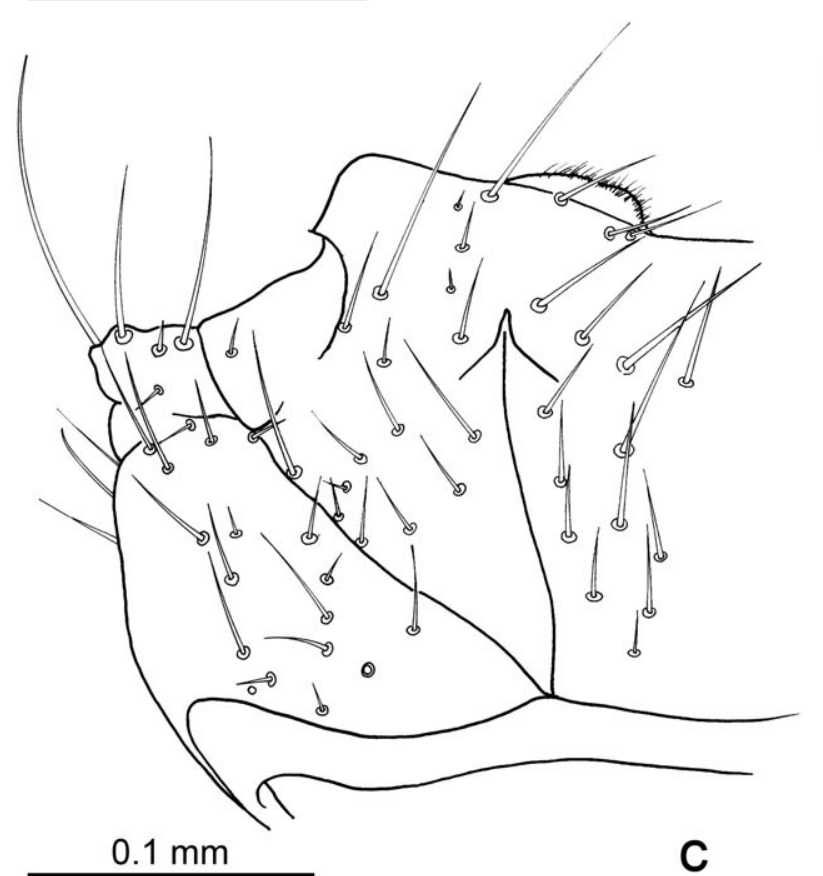

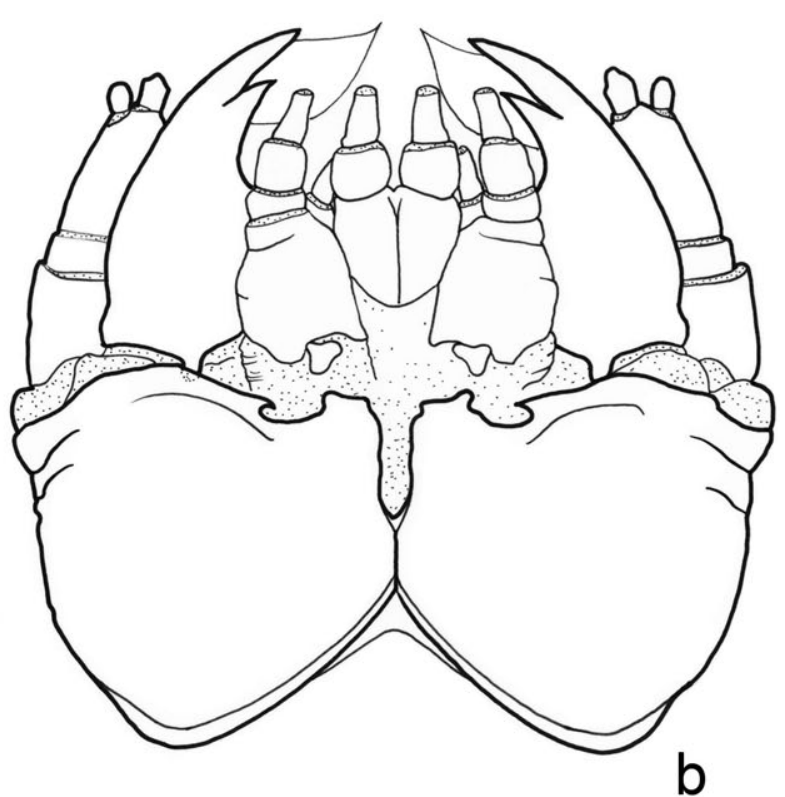

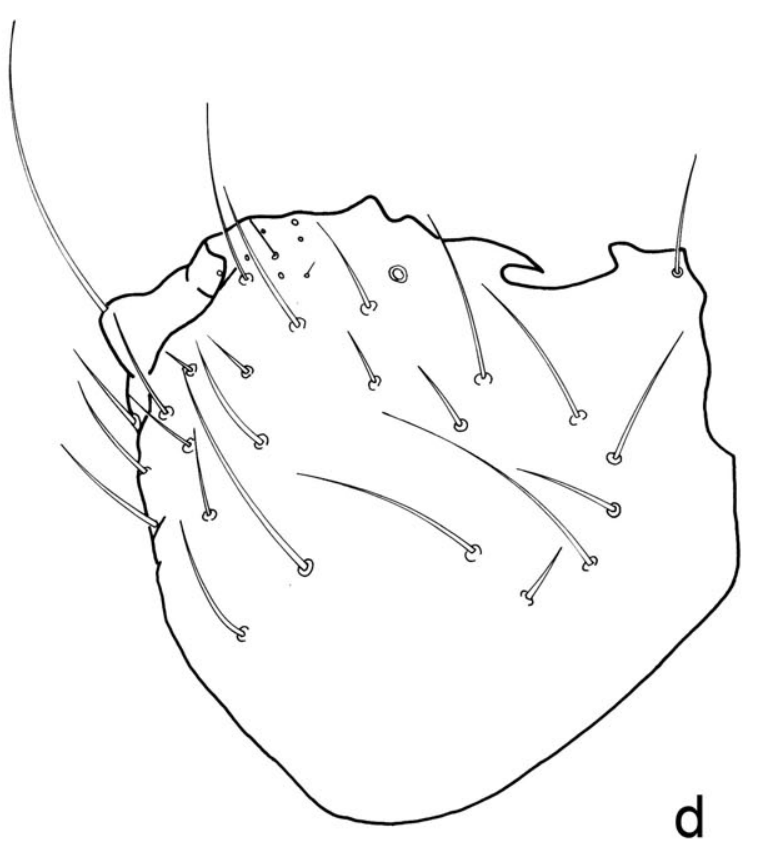

Fig. 2. Paussus favieri first instar larva: $\mathrm{a}$ - head outline, dorsal view; $\mathrm{b}$ - head outline, ventral view; $\mathrm{c}$ - left side of cephalic capsule with setation, dorsal view; $\mathrm{d}$ - right side of cephalic capsule with setation, ventral view.

between the structure in the $P$. favieri larva and the corresponding code is questionable.

\section{RESULTS}

\section{Behavioral observations on Paussus favieri first instar larva}

Immediately after hatching the terminal disk is closed. That is, the dorsal and lateral plates are stuck to the ventral plates (http://tolweb.org/media/44075). The larva actively moves, twisting its head and thorax up, down and side to side for about one hour. After this period of hyperactivity, it remains still, stretching and inflating its body until the terminal disk is completely opened and sclerotized. Once the body becomes white-yellow and head and claws more sclerotized, the larva becomes active again, opening and closing its mandibles (which it can move independently of one another) with abdomen and terminal disk bent dorsally. It is unable to use its short legs for walking, but rather for support. On several occasions we observed the larva grasping the filter paper that lined the observation chamber with its mandibles, thereby creating an anchoring point. The larva would then flex its body vertically, bringing the terminal disk up and over its head (http://tolweb.org/media/44071). We also observed what we interpret to be a "calling behavior" in which the larva balances on its hind legs and urogomphi as it lifts its head and thorax into the air, moving from side to side while 


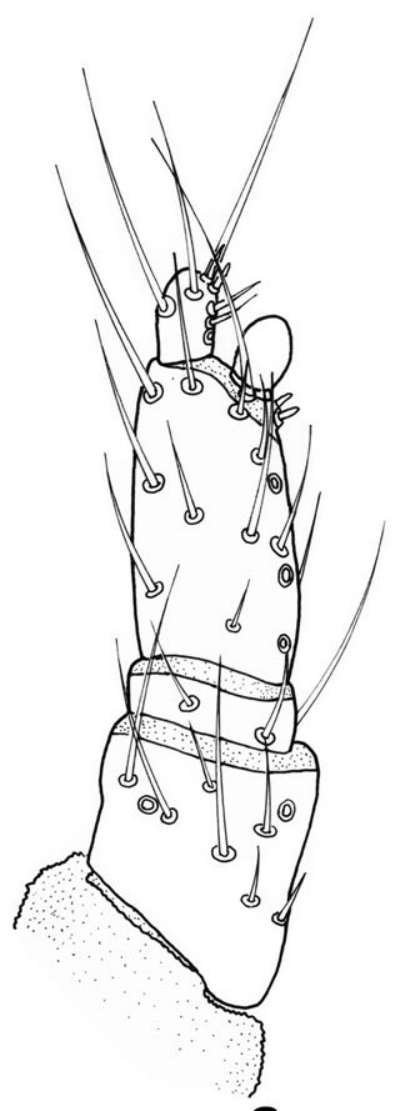

a

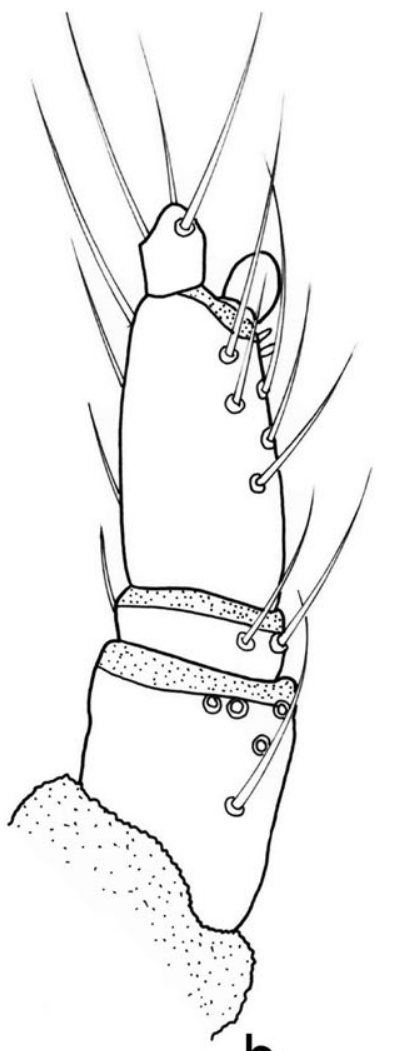

b

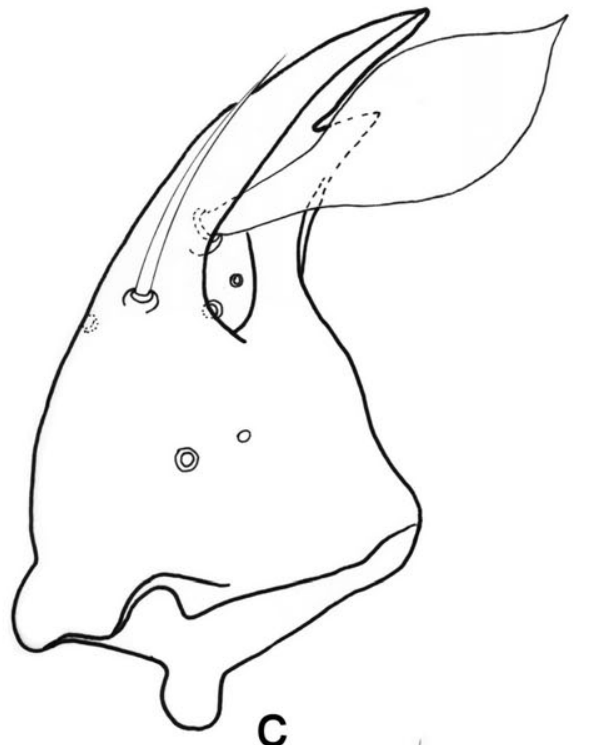

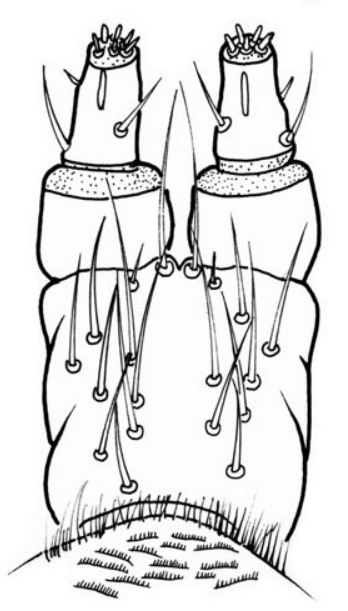

d

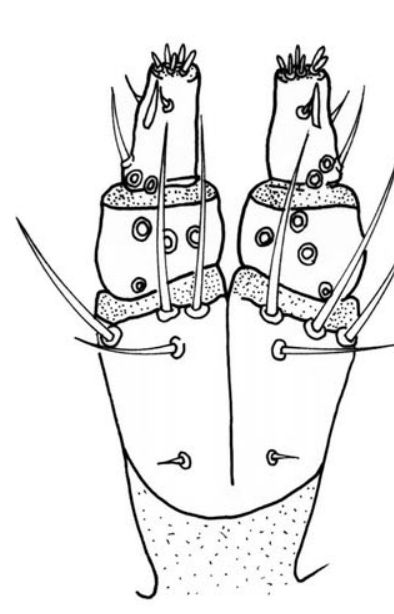

e

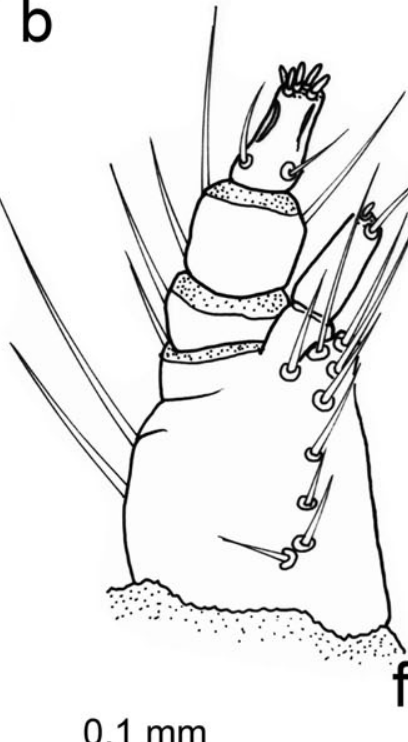

C

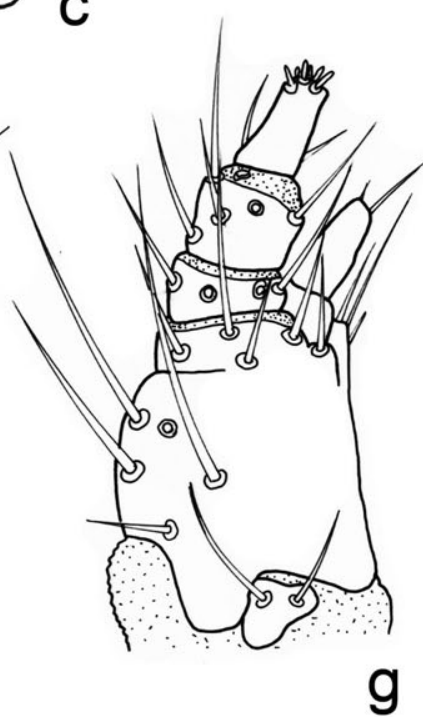

Fig. 3. Paussus favieri first instar larva: a - right antenna, dorsal view; $\mathrm{b}$ - left antenna, ventral view; $\mathrm{c}$ - left mandible, dorsal view; $\mathrm{d}$ - labium, dorsal view; e - labium, ventral view; $\mathrm{f}$ - left maxilla, dorsal view; $\mathrm{g}$ - right maxilla, ventral view.

opening and closing its mandibles, and waving its mid and fore legs (http://tolweb.org/media/44074).

Most often the larva did not show interest toward the host ant brood, but on one occasion we observed an unsuccessful attempt to pierce the brood with its mandibles (http://tolweb.org/media/44076). However, when offered damaged brood the larva began to actively suck the host's hemolymph, demonstrating an aptitude for liquid feeding (http://tolweb.org/media/44077).

\section{Description of Paussus favieri egg and first instar larva}

Egg

Ovoid, whitish, surface reticulation with cell length of 3.5-4.8 $\mu \mathrm{m}$. Egg-shell assignable to type B of Kaupp et al. (2000). Egg length $0.7 \mathrm{~mm}$; width $0.4 \mathrm{~mm}$.

First instar larva

Diagnosis. The presence of a long, broadly lanceolate, distinctly flattened medial mandibular seta (Figs 3c, 7e-f) 


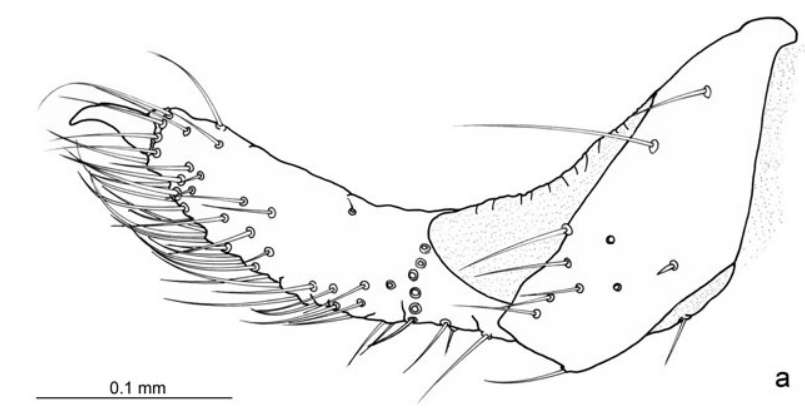

a

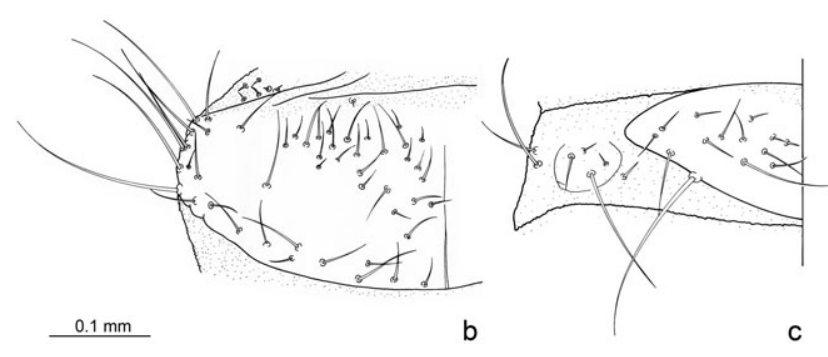

Fig. 4. Paussus favieri first instar larva: a - metathoracic leg, anterior view; $\mathrm{b}$ - left side of pronotum, dorsal view; $\mathrm{c}-$ right side of abdominal sternum III.

easily distinguishes this larva from all known larvae of Paussini.

Measurements. Body length $2.3 \mathrm{~mm}$ (from tip of mandibles to the terminal disk); cephalic capsule maximum width (at base of antennae) $0.45 \mathrm{~mm}$, medial length (from occipital foramen to anterior emargination of frontoclypeolabrum) $0.18 \mathrm{~mm}$, occipital foramen width $0.3 \mathrm{~mm}$; antennal length $0.19 \mathrm{~mm}$; mandible length (measured along outer margin) $0.22 \mathrm{~mm}$, length of modified seta $0.1 \mathrm{~mm}$; pronotum maximum width $0.52 \mathrm{~mm}$, maximum length (along ecdysial suture) $0.2 \mathrm{~mm}$; leg length $0.35 \mathrm{~mm}$; diameter of terminal disk $0.68 \mathrm{~mm}$, dorsal plates length (measured along medial suture) $0.35 \mathrm{~mm}$, urogomphi (ventral plates) length (measured along medial suture) $0.28 \mathrm{~mm}$.

Habitus and coloration. When newly hatched, the larva appears transparent and very soft, except for apex of mandibles and egg-bursters; after sclerotisation, body soft, weakly sclerotised, not physogastric, up-curved (Figs 1, 6a), with cup-shaped, sclerotised, terminal disk (Figs 1, 5, 8 a) held in an elevated position by a flattened, sac-like abdomen (Figs 1, 6a,c). Body white-yellow, semi-transparent; egg-bursters, claws and terminal disk heavily sclerotised and light-brown; mandibles reddish-brown (medially) to dark-brown (at apex).

Microsculpture. Cephalic capsule, mouthparts, thoracic and abdominal tergites, legs and pygidium smooth or irregularly wrinkled to carinate, probably due to incomplete sclerotisation. Basal half of mandibles, dorsally, with irregularly reticulate to scale-like, rugulose microsculpture. Medial region of epipharynx and hypopharynx with multipointed microsculpture, arranged in parallel, transverse rows; lateral margin of frontal emargination and sides of hypopharynx with thin elongate protuberances (Fig. 7f); membranous body areas microgranulate (Fig. 6f); surface of terminal disk densely covered by

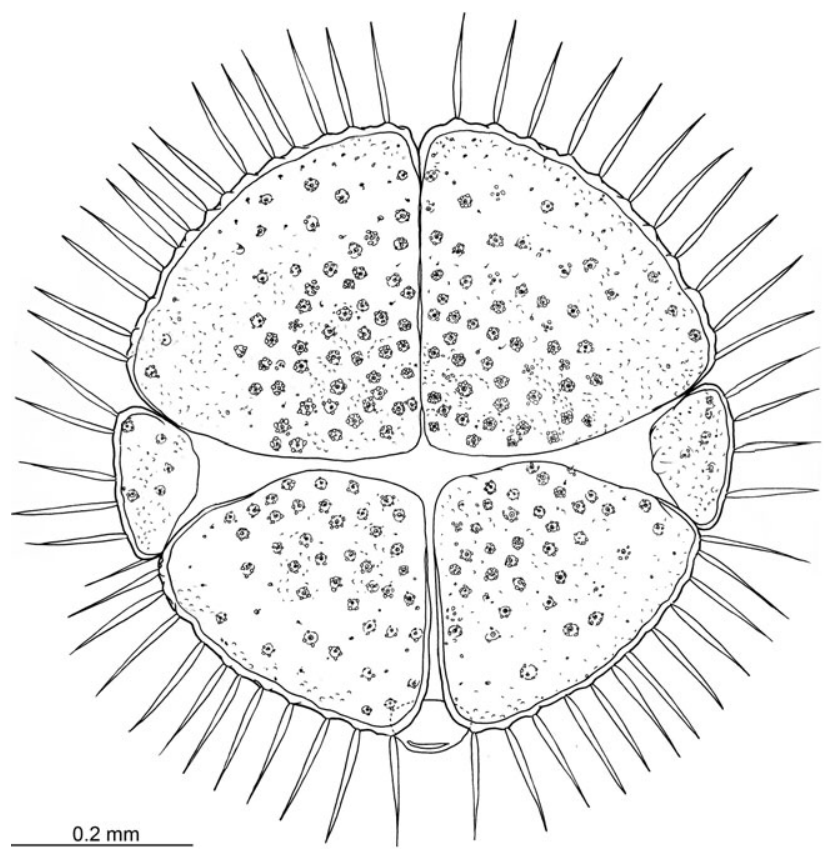

Fig. 5. Paussus favieri first instar larva: terminal disk, caudal view.

finely granulate microsculpture, mixed with sparse, conical spines (Figs 8c-f).

Chaetotaxy. Head. Frontoclypeolabrale with many (about 70) setae of different sizes (identification not possible) and not strictly paired (Figs $2 \mathrm{c}, 7 \mathrm{a}$ ); primary pores apparently absent. Each parietal plate (Figs 2c-d, 7a-b) with about 45 setae of different sizes, about 20 dorsal and about 25 ventrolateral. Antennae (Figs. 3a-b, 7d): Antennomere I with 8 additional setae, mainly dorsally and laterally, all primary pores present; antennomere II with 3 additional setae; antennomere III with 13 setae and 3 pores, mainly on dorsal side, identification with primary structures not possible. Mandible (Figs 3c, 7e-f) with seta MN1* dorsolateral, elongate, bent inward; seta $\mathrm{MN}_{2}{ }^{*}$ modified into a long, broadly lanceolate, distinctly flattened structure, directed mesad; 5 pores present on each mandible: $\mathrm{MN}_{\mathrm{a}}$ lateral, $\mathrm{MN}_{\mathrm{b}}{ }^{*}$ and additional pore mesodorsal, $\mathrm{MN}_{\mathrm{c}}{ }^{*}$ and additional pore more distally, close to base of modified $\mathrm{MN}_{2} *$. Setal group $\mathrm{gMX}$ on stipes with 9 setae: 4 longitudinally lined and 5 on the remnant of lacinia (?); about 9 setae present on lateral and ventral sides of stipes: 5 at the level of the partially fused palpomere I (including $\mathrm{MX}_{10}$ ) and 4 mesolaterally (2 lateral possibly being $\mathrm{MX}_{2}$ and $\mathrm{MX}_{3}$ ); apex of galeomere II with $\mathrm{MX}_{9} *$ long and small blunt-tipped sensorial papilla; maxillary palpomeres as follows: II with $\mathrm{MX}_{\mathrm{e}}$ and $\mathrm{MX}_{\mathrm{f}}$ ventral and 2 additional setae, one lateral and one mesal; III with 4 dorsal setae and 2 pores; IV with 2 additional setae subbasally on ventral side, 3 slender digitiform sensilla subapically and one apical sensorial area with about 9 elongate subequal papillae (sensilla basiconica); cardo with 2 setae (mesal possibly $\mathrm{MX}_{1}$ ); pores $\mathrm{MX}_{\mathrm{a}}$ and $\mathrm{MX}_{\mathrm{b}}$ not visible. Dorsal and lateral setae on prementum moderately long and hair-like, ventral setae elongate and curved; LA $_{6}$ subapical, much longer than palpomere I; 8 

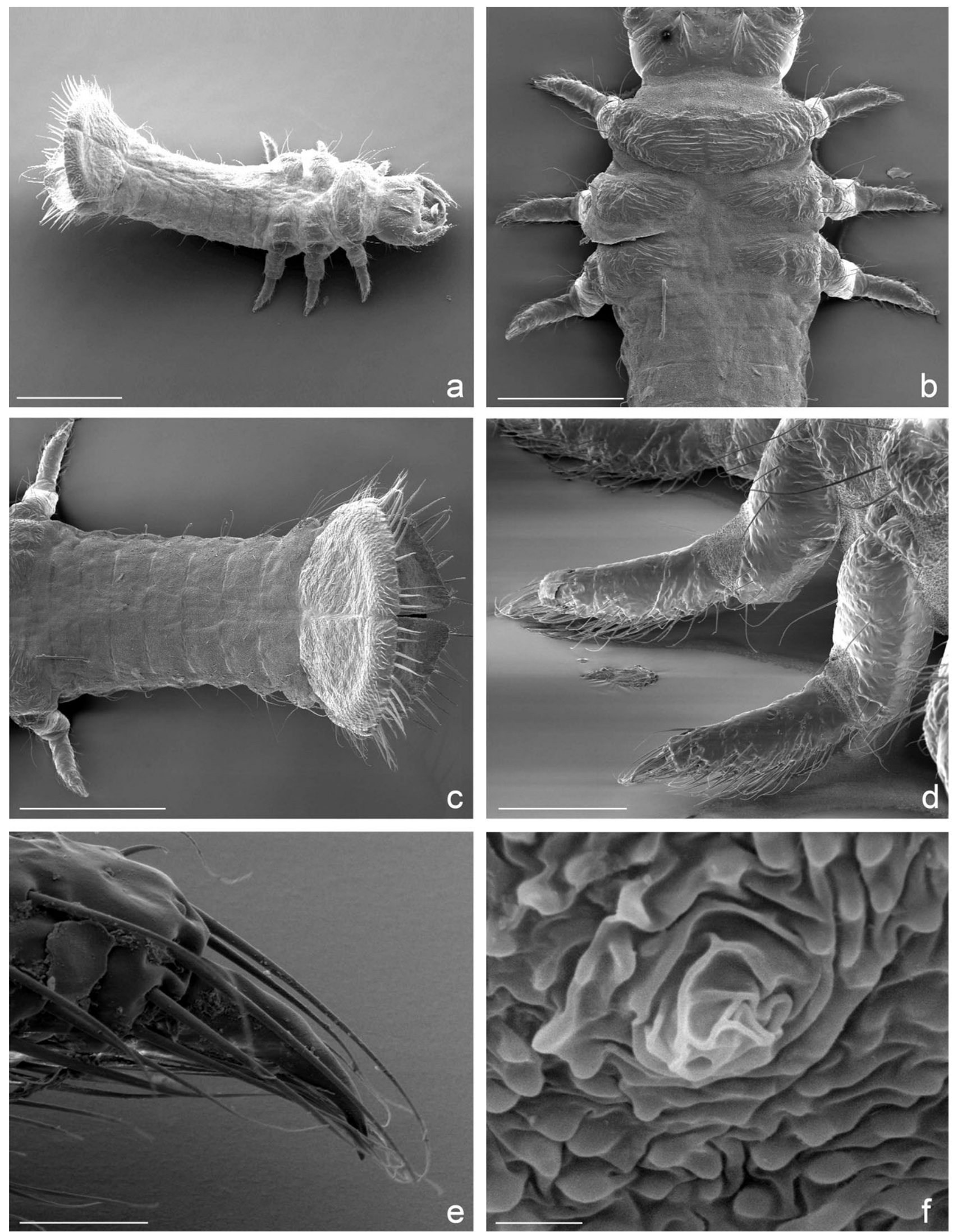

Fig. 6. Paussus favieri, SEM images of first instar larva: $\mathrm{a}$ - habitus, right dorsolateral view; $\mathrm{b}$ - thorax, dorsal view; $\mathrm{c}$ - abdomen, dorsal view; $\mathrm{d}$ - right legs of pro and mesothorax, anterior view; e - left prothoracic claw; $\mathrm{f}$ - right mesothoracic spiracle. Scale bars: $\mathrm{a}=500 \mu \mathrm{m} ; \mathrm{b}=300 \mu \mathrm{m} ; \mathrm{c}=400 \mu \mathrm{m} ; \mathrm{d}=100 \mu \mathrm{m} ; \mathrm{e}=20 \mu \mathrm{m} ; \mathrm{f}=5 \mu \mathrm{m}$. 

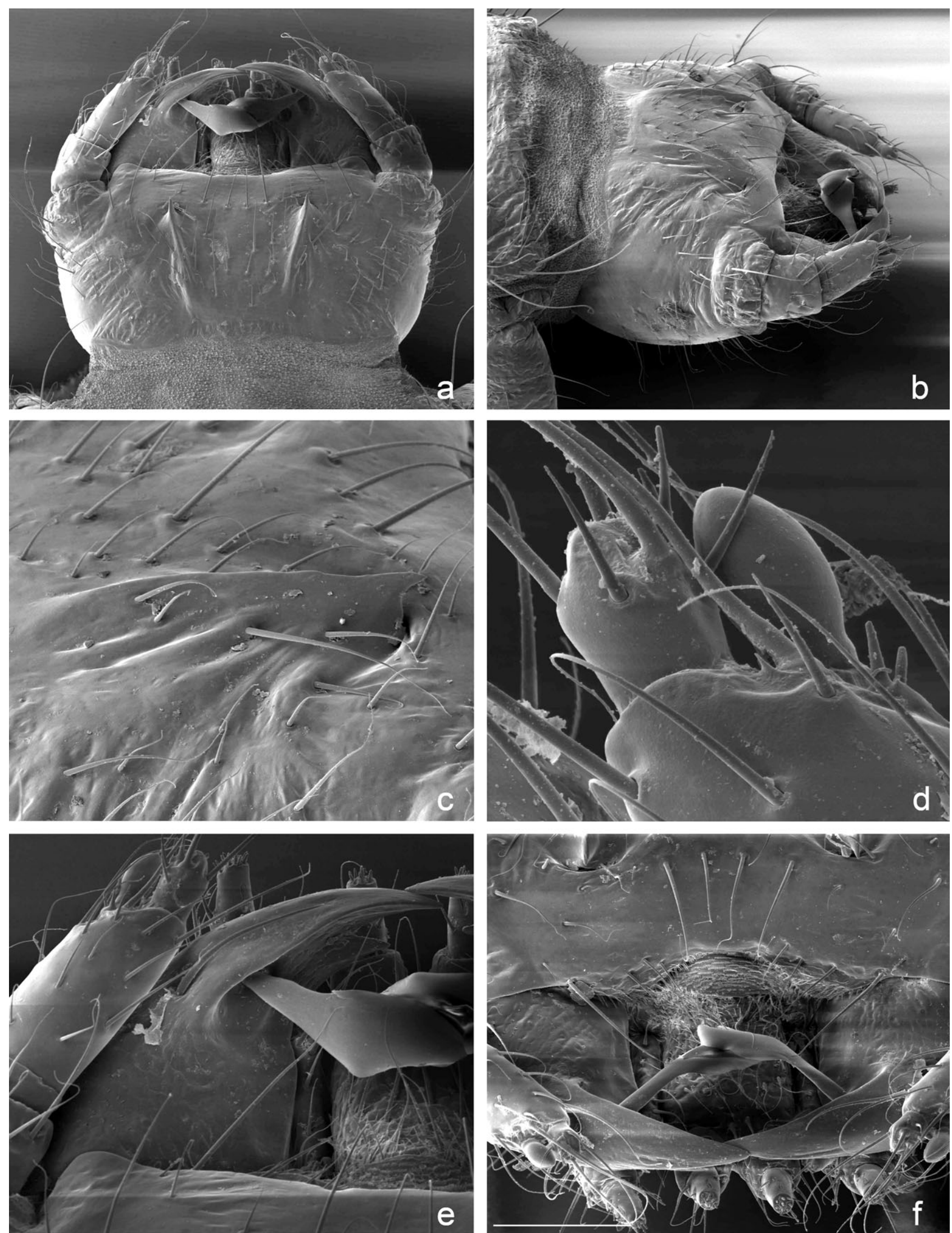

Fig. 7. Paussus favieri SEM images of first instar larva: a - head, dorsal view; $\mathrm{b}$ - head, right dorsolateral view; $\mathrm{c}-$ right eggburster, right lateral view; $\mathrm{d}$ - apex of right antenna, dorsal view; e - left mandible, dorsal view; $\mathrm{f}$ - mouthparts, anterodorsal view. Scale bars: $a-b=100 \mu \mathrm{m} ; \mathrm{c}, \mathrm{e}, \mathrm{f}=50 \mu \mathrm{m} ; \mathrm{d}=10 \mu \mathrm{m}$. 
pairs of setae dorsally on prementum, $\mathrm{LA}_{3-5}$ not possible to identify; ventrally $\mathrm{LA}_{1}$ basally close to midline, 4 pairs of setae ( $\mathrm{LA}_{2}$ and 3 additional setae) apically; labial palpomeres as follows: I with 4 pores ventrally (including $\mathrm{LA}_{\mathrm{b}}$ ); II with 3 additional setae: 1 short, dorsal, and 2 lateral ( 1 basal spiniform and 1 more distal very short); 2 slender digitiform sensilla subapically and one apical sensorial area with about 9 elongate subequal papillae (sensilla basiconica), similar to those of maxillary palpomere IV. Thorax. Pronotum (Figs 4b, 6b) with about 55 setae on each side of ecdysial suture (primary setae impossible to identify); notopleural setae very long and thin; mesonotum and metanotum (Fig. 6b) with about 15 setae on each side of ecdysial line. Distal leg segment (corresponding to fused trochanter, femur, tibia and tarsus) with a tuft of about 70-80 long and thin setae, surrounding also the apical claw (Figs 4a, 6d-e). Sternal areas of pro-, meso- and metathorax with about 10 pairs of setae, mesal ones longest. Abdomen. Terga of abdominal segments I-VII (Fig. 4c) with about 20 pairs of setae each (identification not possible) and no pores. Dorsal and lateral plates of terminal disk dorsally (tergal side, Fig. 8b) with many short, spiniform, regularly spaced (every 20-40 $\mu \mathrm{m})$ sensilla S-VII: about 150 (mostly on subapical area) on each dorsal, about 15 on each lateral plate; each ventral plate (urogomphus) with about 50 long setae on ventral side; perimeter of disk (margin of dorsal, lateral and ventral plates) with about 55 elongate $(120-130 \mu \mathrm{m})$ sensilla S-II (Figs 5, 8c), regularly spaced at margin of plates and urogomphi, radially oriented to the surface of terminal disk: $10-13$ on each dorsal plate, 5 on each lateral plate and about 11-12 on each urogomphus; each sensillum S-II lanceolate, straight or slightly curved and pointed apically, basally tapered and inserted in a sunken socket; dorsal surface longitudinally keeled (9 slightly protruding carinae) and bearing irregular pits (about 2 $\mu \mathrm{m}$ ), giving it a spongy appearance (Fig. 8c). Dorsal surface of terminal disk with many sensilla S-I (Figs 5, $8 \mathrm{~d}-\mathrm{e})$ : about 55 on each dorsal plate, $5-6$ on each lateral plate and about 40 on each ventral plate (urogomphi); each sensillum S-I composed of a dome-like protruding base (diameter 15-18 $\mu \mathrm{m}$, height $8-10 \mu \mathrm{m}$ ), subapically with a crown of 4-6 multispinulated lobes and apically with a medial short seta $(3-4 \mu \mathrm{m})$, expanded and multispinulated at apex (Fig. 8e); S-I with longer frayed seta and smooth conical base regularly alternating with S-II along entire margin of plates; 4 spiniform sensilla emerging from medial apex of dorsal plates. Dorsal plates and urogomphi with many scattered filiform microstructures $0.4 \mu \mathrm{m}$ thick (Fig. 8f) emerging from cuticular pores (diameter $2.5 \mu \mathrm{m}$ ). Epipleurites of abdominal segment I with 1 or 2 setae each; epipleurites of abdominal segments II-VII with 4-6 setae each. Hypopleurites of abdominal segments I-VII with 3-5 additional setae each. Sternal areas (Fig. 4c) with 20-30 setae on each abdominal segment (homologisation not possible). Pygidium without setae.

Head. Strongly transverse (Figs $2 \mathrm{a}-\mathrm{b}, 7 \mathrm{a}$ ), two times as wide as long, prognathous, subparallel-sided, basally nar- rowed, with maximum width at base of antennae; cephalic capsule steeply sloped dorsally from base to apex, not retracted into prothorax (Fig. 7a); base of head capsule and occipital foramen lined with a sclerotized band. Frontoclypeolabrale sub-hexagonal (Fig. 2a); anterior margin not sclerotized, distinctly concave, medially very thin and slightly emarginated; surface distinctly convex posteriorly and anterolaterally, deeply concave anteromedially; transverse frontal keel absent; eggbursters well developed, consisting of two strongly sclerotized longitudinal keels, posteriorly slightly convergent, ending anteriorly in a sharply pointed spine directed anteriorly (Figs 2a, 7a-c); coronal suture absent; frontoclypeolabrale almost fused with parietalia, frontal sutures very fine but still visible in light microscope. Parietalia (Figs 2a-c, 7a-b) subparallel-sided, without stemmata, protruding at base of antennae; ventral walls of parietalia medially fused into a short gular suture. Antennae (Figs 2a, 3a-b, 7a, d) 4-jointed, directed forward and slightly convergent anteriorly, not reaching apices of the mandibles, inserted in extensive membranous, soft elevations; antennomeres I-III wide; I asymmetrical, shorter on ental side, slightly longer than broad, more than three times as long as II; II short, three times wider than long; III about six times as long as II; II slightly shorter than IV; IV very small compared to others; sensorial appendage ovoid, positioned ventrolaterally on antennomere III (Fig. 7d), about as long as IV. Mandibles (Figs 3c, 7e) subtriangular, slightly falcate apically, 1.5 times as long as wide at base, with single, ventral cutting edge; dorsal surface deeply excavate along occlusal margin, particularly at base of modified mandibular seta; retinaculum slender, triangular, sharp and pointed, displaced and directed apically, forming, together with the pointed apex, a bidentate mandible; prostheca and penicillus absent. Maxilla (Figs 3f-g) with small, subtriangular cardo and subquadrate stipes; maxillary palpus 4-jointed: I partially fused with stipes, about twice wider than long; II slightly longer than I; III subquadrate, twice as long as II; IV conical and subulate; galea 1-jointed (corresponding to galeomere II of Ozaenini, galeomere I being fused with stipes), digitiform, almost straight, distinctly tapered from base to apex; lacinia small, vestigial; lateral margin of stipes distinctly curved, occlusal margin straight without basal tooth. Labium composed of a membranous mentum, ventrally sclerotised prementum and 2-jointed palps. Prementum (Figs 3d-e) slightly enlarged from base to apex, particularly in ventral view; basal half of prementum dorsally bulging, distal half with vestigial subapical ligula, represented by prominent bases of strong setae $\mathrm{LA}_{6}$. Labial palpomeres subequal in legth: I subquadrate, II conical, subulate (Figs 3d-e). Hypopharynx densely covered by transverse parallel rows of pointed papillae (Fig. $7 \mathrm{f}$ ), closely fitting in the vault of the oral cavity.

Thorax. Thoracic segments (Figs 1, 6b) slightly sclerotised; tergites, pleurites and sternites poorly delimited, mostly recognizable by their setae and a smooth surface; tergites similar in length, widely transverse with slightly rounded (pronotum) or straight (meso- and metanotum) 

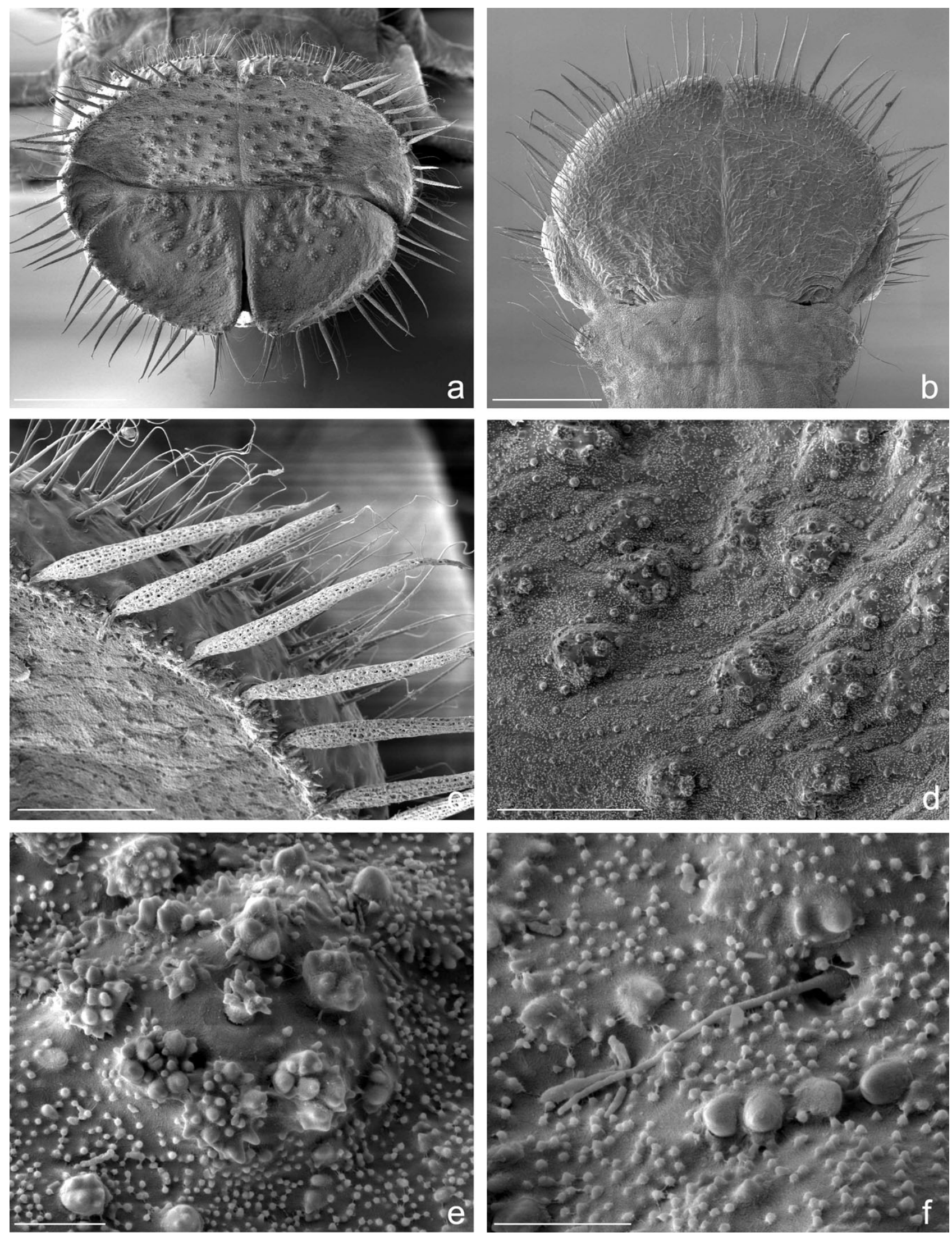

Fig. 8. Paussus favieri SEM images of first instar larva: a - terminal disk, apical view; $\mathrm{b}$ - terminal disk, dorsal view; $\mathrm{c}-\mathrm{dorsal}$ plates, marginal sensilla S-II; d - dorsal plates, sensilla S-I; e - dorsal plates, sensillum S-I; f - dorsal plates, filiform structure (glandular pore with substance? sensillum?). Scale bars: $a=300 \mu \mathrm{m} ; \mathrm{b}=200 \mu \mathrm{m} ; \mathrm{c}=30 \mu \mathrm{m} ; \mathrm{d}=40 \mu \mathrm{m} ; \mathrm{e}=5 \mu \mathrm{m}$. 
sides; surface of tergites irregularly convex (Fig. 6b); longitudinal ecdysial line restricted to pronotum. Pronotum composed of single distinct sclerite, slightly concave anteriorly and convex posteriorly, about three times as wide as long. Mesonotum and metanotum, with tergites longitudinally subdivided into two subtriangular parts, widely separated by membranous integument. Sterna of thoracic segments soft, unsclerotised.

Spiracles. All spiracles annular-uniforous (Fig. 6f); peritreme dome-shaped, convex and with a round hole at top; atrium poorly developed. Mesothoracic spiracles between pro- and mesonotum similar to but slightly larger than abdominal spiracles, with wider atrium; small rudimentary spiracles present in metapleura. Abdominal spiracles I-VIII dorsolateral, partially sunken in bulged membranous areas above epipleura (Fig. 1).

Legs. Short and highly modified, all similar in type and length (Figs 4a, 6d), composed of 2 joints subequal in length: basal joint representing coxa, basally embedded into soft membranous areas, dorsally articulated with medially subdivided pleural sclerite; distal part of coxa obliquely truncate to allow folding of second joint; latter cylindrical, digitiform, slightly tapered to apex, composed of completely fused trochanter, femur, tibia and tarsus; sutures between segments hardly visible. Procoxae more slender and shorter than meso- and metacoxae. Second joint bearing single conspicuous claw (Figs 4a, 6e), apically curved and pointed.

Abdomen. Subparallel-sided, gradually enlarged toward teminal disk, scarcely or not sclerotised, distinctly curved in an upturned position (Figs 1, 6a, c); narrowest at segments III-V; terga flattened or slightly convex, pleura and sterna swelling. Terminal disk (Figs 5, 8a-b) wider than segment VII, regularly round, with perimeter strongly raised, corrugated and markedly sclerotized; disk composed of 6 symmetrical subtriangular plates joined by thin membranous lines; dorsal plates wider than others, medially convex and bearing abundant sensilla S-I; lateral plates small; ventral plates corresponding to modified urogomphi, similar in shape to dorsal plates, with surface flattened or slightly concave. Pygidium cylindrical, dorso-ventrally flattened, ventral to urogomphi.

Material examined. Two first instar larvae hatched in captivity on 28.v.2009 from eggs laid on 17.v.2009 by a female collected from a nest of Pheidole pallidula, Morocco, High Atlas Mountains, Oukaimeden, $2235 \mathrm{~m}$ a.s.1. $\left(31.23792^{\circ} \mathrm{N}\right.$, 7.81724 ${ }^{\circ}$ ), on 13.v.2009. Deposited in the A. Di Giulio collection (Roma, Italy).

\section{DISCUSSION}

Within the subfamily Paussinae, larvae are known from 4 of the 5 tribes (Metriini, Mystropomini, Ozaenini, Paussini), the larvae of Protopaussini being still unknown. Within these tribes, only one or few species of 11 genera (out of 46; Lorenz, 2005) are known as larvae, often described based on a single specimen of second and/or third instar. Though our knowledge of Paussinae larvae is very limited, the taxon sampling is broad enough to provide information about relationships among major clades. However since larvae are rarely collected in the field and difficult to rear in the laboratory, phylogenetic analyses based on larval morphology compared different instars of the taxa included in the analyses (Bousquet, 1986; Beutel, 1992; Vigna Taglianti et al., 1998; Di Giulio et al., 2003; Di Giulio \& Moore, 2004). For this reason, only morphological characters related to shape of the head capsule, head appendages, legs and terminal disk have been used. It has not been possible to include first instar larval characters, such as those related to eggbursters or primary chaetotaxy (Bousquet \& Goulet, 1984), which are widely acknowledged to be phylogenetically informative (Bousquet \& Goulet, 1984; Bousquet, 1986; Arndt, 1998; Meier \& Lim, 2009). In fact, until now first instar larvae in Paussinae were known for only four species: Metrius contractus (Metriini), Pachyteles vignai Deuve, 2000 (Ozaenini), Goniotropis kuntzeni (Bänninger, 1927) (Ozaenini), and Arthropterus sp. (Paussini).

The discovery, description and observations of the 1st instar larva of Paussus favieri presented herein are significant in many respects. First the paper provides information about the larval stage, behavior, and life cycle of a rare species that is increasingly endangered due to the destruction of suitable habitats ( $P$. favieri is endemic to the Mediterranean Region, and is one of only two species of Paussini occurring in Europe). It also increases the number of described myrmecophilous larvae, thereby broadening our understanding of evolutionary adaptations to a myrmecophilous life in Paussini. In the following discussion, the morphological characters observed in $P$. favieri 1 st instar larva are analyzed and discussed in comparison with those of Arthropterus sp., the only other known species of the Paussini.

All the synapomorphic characters of Paussini (Di Giulio \& Moore, 2004) are found in the larva of Paussus favieri, including: Neck not constricted, head prognathous, coronal suture absent, antenna short and broadly inserted in bulging membranous base, large antennal sensorial appendage, mandibles short and pointed with some long setae, stipes without basal tooth, setal group gMX extremely reduced, prementum bulging, one tarsal claw, urogomphi plate-like, terminal disk perfectly round, pygidium ventral to urogomphi.

Most Paussini larvae have an elongate digitiform prostheca, a soft structure with an anterior ridge that almost reaches the apex and arises near the base of the ental surface of the mandible. Surprisingly, the prostheca is not present in the 1 st instar of $P$. favieri, although it has been considered a synapomorphy of the Paussina + Platyrhopalina. While $P$. favieri does not have a prostheca, it does have a similar structure that is apparently homologous to the medial mandibular seta $(\mathrm{MN} 2 *)$. It is a long, broadly lanceolate, distinctly flattened structure (Figs 2a, 3c, $7 \mathrm{a}, \mathrm{e}-\mathrm{f}$ ), arising from an area behind the cutting edge of mandible. The functions of the prostheca and of this similar structure in $P$. favieri are unknown, but possibly these larvae have a specialized feeding strategy that may include soliciting trophallaxis from the host ants. 
The reduction of the base of the cephalic capsule (frontale + parietalia), with loss of coronal suture and basal part of frontal sutures up to the base of the egg bursters, is shared by the larvae of P. favieri (Figs 2a, 7a) and other known larvae of the Paussini subtribes Paussina and Platyrhopalina, being possibly their synapomorphy (Di Giulio \& Moore, 2004). This reduction from the ancestral state found in other Paussinae tribes (e.g., Metriini, Ozaenini) may be related to the secondary acquisition of a prognathous position of mouthparts and head derived from a hyperprognathous ancestral state (Di Giulio et al., 2003). Such a basal degeneration of the head (including the widening of the occipital foramen and a disappearance of the neck) could be an adaptation for living with ants.

As in all known larvae of Paussina, the basal maxillary palpomere and the stipes of $P$. favieri are partially fused (Figs 3f-g); in some other Paussus species this fusion is complete. A small remnant lacinia is present in $P$. favieri (Fig. 3f), whereas it is completely absent in other Paussina and Platyrhopalina. Arthropterus has a highly derived lacinia with a row of strong hook-like setae.

In contrast to the larva of Arthropterus, which has distinct and functional leg articles, the trochanter, femur, tibia, and tarsus of P. favieri are fused (Fig. 4a) and remnant sutures are only visible with SEM (Fig. 6d). Such fusion is a synapomorphy of Paussina and Platyrhopalina, though in Platyrhopalopsis traces of oblique sutures between the fused articles are clearly visible. The reduction from two (Metriini + Mystropomini + Ozaenini) to one claw seems to be a defining character of Paussini. Most Paussina and Platyrhopalina larvae have a very small and thin tarsal claws, whereas Arthropterus and $P$. favieri larvae have conspicuous, robust tarsal claws. It is possible that this is a characteristic of all first instar larvae as compared with latter instars.

As in the other Paussus larvae (Paussina) and in Platyrhopalopsis (Platyrhopalina), an anterior medial emargination of frontoclypeolabrale is present in $P$. favieri (Figs 2a, c, 7a), while this modification is absent in the Arthropterus larva. For this reason we consider this character to be synapomorphic of the subtribes Paussina and Platyrhopalina. In $P$. favieri, we observed that the medial anterior margin moves during liquid feeding and we predict that this movement may increase the efficiency of suction.

There are several differences between the terminal disk of the first instar Arthropterus and P. favieri larvae (Figs $5,8 \mathrm{c}, \mathrm{e})$ :

(1) The marginal setae of $P$. favieri are lanceolate, thin, with a pointed tip, while in Arthropterus they are clavate (sensilla S-VIII of Di Giulio \& Moore, 2004, possibly homologous to sensilla S-II). Such a feature has not been observed in any other larva of Paussini and could be a feature only present in the first instars. In P. favieri a dense substance emerges from the bases of these setae and runs onto the surface of the disk. A possible glandular function was also reported for the homologous setae of Arthropterus sp. (Di Giulio \& Moore, 2004). The different shapes of these setae could be functionally related to different ways of supplying the substance to the ants, from the apex of the club-shaped sensilla in Arthropterus, or from the surface of the cup-shaped terminal disk in $P$. favieri.

(2) The disk of P. favieri is cup-shaped, as in all species of the subtribes Paussina and Platyrhopalina, with upcurved margin, while in Arthropterus the disk is biconvex with a simple margin.

(3) The dorsal plates of P. favieri are slightly wider than ventral plates, and the lateral plates are small, while in Arthropterus the dorsal plates are almost twice as large as the ventral, and the lateral plates are wide.

(4) The sensilla S-I located on the terminal disk are complex with multispinulate, dome-like bases and short fringed setae in P. favieri, whereas the homologous structures in Arthropterus are short, simple and coniform, bearing an elongate, simple, blunt-tipped seta.

Nothing is known about the way of life of Paussini larvae except for several field observations which confirm that they are myrmecophilous. In most cases larvae have been found inside ant nests or carried about by the host ants (Luna de Carvalho, 1959, 1992; Geiselhardt et al., 2007). No data on oviposition, feeding, development or behavior are available, not even for the first instar larvae of Arthropterus, hatched in captivity from eggs laid by an unidentified female (Di Giulio \& Moore, 2004). Various authors have speculated that Paussini larvae feed on host brood and that the round cup-shaped terminal disk is probably adapted for supplying attractive substance to worker ants (Oberprieler, 1985; Luna de Carvalho, 1992). Based on the observation of several characters, unusual for a predaceous carabid larva (i.e., shortened and somewhat degenerated head capsule, reduced mouthparts, unique presence of a prostheca, partial atrophy of legs), Di Giulio (2008) advanced the possibility that they could at least partially be fed by the ants through trophallaxis. The behavioral observations reported here do not exclude this hypothesis. In fact, the "calling behavior" described above (first paragraph of Results section) is similar to that reported for ant larvae soliciting trophallaxis (Hölldobler \& Wilson, 1990).

\section{REFERENCES}

ARNDT E. 1998: Phylogenetic investigation of Carabidae (Coleoptera) using larval characters. Phylogeny and classification of Caraboidea (Coleoptera: Adephaga). In Ball G.E., Casale A. \& Vigna Taglianti A. (eds): Proceedings of the XX International Congress of Entomology (28 August, 1996, Florence, Italy). Museo Regionale di Scienze Naturali, Torino, pp. 171-190.

Beutel R.G. 1992: Study on the systematic position of Metriini based on characters of the larval head (Coleoptera: Carabidae). Syst. Entomol. 17: 207-218.

BousQuet Y. 1986: Description of first-instar larva of Metrius contractus (Coleoptera: Carabidae) with remarks about phylogenetic relationships and ranking of the genus Metrius. Can. Entomol. 118: 373-388.

Bousquet Y. \& Goulet A. 1984: Notation of primary setae and pores on larvae of Carabidae (Coleoptera: Adephaga). Can. J. Zool. 62: 573-588. 
Bøving A.G. 1907: Om Pauddiderne og Larven til Paussus Kannegieteri Wasm. [About the paussids and the larva of Paussus kannegieteri Wasm.] Vidensk. Meddr. Dansk Naturh. Foren. (Kjøbenhavn) 9: 109-136.

BRAUNS H. 1914: Descriptions of some new species of myrmecophilous beetles from Southern Rhodesia. Proc. Rhod. Scient. Assoc. 13: 32-42.

Casale A., Sturani M. \& Vigna Taglianti A. 1982: Coleoptera. Carabidae. I. Introduzione, Paussinae, Carabinae. Fauna d'Italia, 18. Edizioni Calderini, Bologna, xii + $499 \mathrm{pp}$.

Costa C., Vanin S.A. \& Casari-Chen S.A. 1988: Larvas de Coleptera do Brasil. Museu de Zoologia, Universidade de Sao Paulo, Sao Paulo, 282 pp. +165 pls.

Darlington P.J. JR 1950: Paussid beetles. Trans. Am. Entomol. Soc. 76: 47-142.

Di GiUlio A. 1999: Aspetti morfologici, ultrastrutturali ed ecoetologici degli stadi preimmaginali dei Paussidi e loro implicazioni filogenetiche (Coleoptera: Caraboidea). Ph.D. thesis, Università di Roma "La Sapienza", 221 pp.

Di Givlio A. 2008: Fine morphology of the myrmecophilous larva of Paussus kannegieteri (Coleoptera: Carabidae: Paussinae: Paussini). Zootaxa 1741: 37-50.

Di Giulio A. \& Moore W. 2004: The first-instar larva of the genus Arthropterus (Coleoptera: Carabidae: Paussinae): implications for evolution of myrmecophily and phylogenetic relationships within the subfamily. Invertebr. Syst. 18: 101-115.

Di Giulio A. \& Moore W. 2009: The first known larva of the Australian genus Mystropomus Chaudoir (Coleoptera: Carabidae: Paussinae). Aust. J. Entomol. 48: 140-148.

Di Giulio A. \& Vigna Taglianti A. 2001: Biological observations on Pachyteles larvae (Coleoptera: Carabidae: Paussinae). Trop. Zool. 14: 157-173.

Di Giulio A., Fausto A.M., Taddei A.R. \& Vigna Taglianti A. 2000: The terminal disk of Pachyteles larvae (Coleoptera, Carabidae, Paussinae): a morphological study. In Brandmayr P., Lövei G., Zetto Brandmayr T., Casale A. \& Vigna Taglianti A. (eds): Natural History and Applied Ecology of Carabid Beetles. Proceedings of the IX European Carabidologists' Meeting (26-31 July, 1998, Camigliatello, Cosenza, Italy). Pensoft, Sofia, Moscow, pp. 89-93.

Di Giulio A., Fattorini S., Kaupp A., Vigna Taglianti A. \& NaGel P. 2003: Review of competing hypotheses of phylogenetic relationships of Paussinae (Coleoptera: Carabidae) based on larval characters. Syst. Entomol. 28: 509-537.

van EMden F. 1922: Über die Larven der Paussiden und Beschreibung der Larve des Paussus granulatus Westw. (Col.). Entomol. Blätt. 18: 37-47.

Geiselhardt S.F., PeschKe K. \& Nagel P. 2007: A review of myrmecophily in ant nest beetles (Coleoptera: Carabidae: Paussinae): linking early observations with recent findings. Naturwissenschaften 94: 871-894.

HARRIS R.A. 1979: A glossary of surface sculpturing. Occas. Pap. Bur. Entomol. Calif. Dep. Agric. 28: 1-31.

Hölldobler B. \& Wilson E.O. 1990: The Ants. Springer, Berlin, $732 \mathrm{pp}$.

KaupP A. \& RöDEl M.O. 1997: Ein neuer westafrikanischer Paussus Linnaeus aus der P. favieri Gruppe (Coleoptera: Carabidae: Paussinae). Koleopt. Rdsch. 67: 5-12.

LAWRENCE J.F. 1991: Order Coleoptera. In Stehr F.W. (ed.): Immature Insects. Vol. 2. Kendall/Hunt, Dubuque, Iowa, pp. 144-298.
Lorenz W. 2005: Systematic List of Extant Ground Beetles of the World (Coleoptera "Geadephaga": Trachypachidae and Carabidae Incl. Paussinae, Cicindelinae, Rhysodinae), 2nd $e d$. Published by the author, Tutzing, Germany, $530 \mathrm{pp}$.

Luna de Carvalho E. 1959: Notas sobre Paussideos (Col. Carab. Isochaeta). Subsídios para o estudo da biologia na Lunda. Publições Cult. Co. Diam. Angola 48: 51-90.

Luna de Carvalho E. 1980: Notas Coleopterológicas (V. nota). Bol. Soc. Port. Ciéncias Nat. (2a sér.) 21: 5-6.

Luna de Carvalho E. 1989: Essay Monographique des Coléoptèteres Protopaussines et Paussines. Memorias do Institudo de Investigaçao Científica Tropical (segunda série) (Lisboa) No. 70 [1987], 1028 pp.

Luna de Carvalho E. 1992: Revisao do estudio das larvas de Carabideos Paussinae e de subfamilias afinis (Coleopteras: Adephaga). Elytron (Barcelona) 5 [1991]: 285-310.

Meier R. \& Lim G.S. 2009: Conflict, convergent evolution, and the relative importance of immature and adult characters in endopterygote phylogenetics. Annu. Rev. Entomol. 54: 85-104.

Moore W. \& Di Giulio A. 2006: Description and behaviour of Goniotropis kuntzeni larvae (Coleoptera: Carabidae: Paussinae: Ozaenini) and a key to genera of Paussinae larvae. Zootaxa 111: 1-19.

NAGEL P. 1979: Aspects of the evolution of myrmecophilous adaptations in Paussinae. In Den Boer P.J., Thiele H.U. \& Weber F. (eds): On the Evolution of Behaviour in Carabid Beetles. Agricultural University Wageningen, Miscellaneous Papers No. 18, pp. 15-34.

NAGEL P. 1987: Arealsystemanalyse afrikanischer Fühlerkäfer (Coleoptera, Carabidae, Paussinae). Ein Beitrag zur Rekonstruktion der Landschaftsgenese. Erdwissenschaftliche Forschung, 21. Franz Steiner Verl., Wiesbaden, Stuttgart, 233 pp.

NAGel P. 1997: New fossil paussids from Dominican amber with notes on the phylogenetic systematics of the paussine complex (Coleoptera: Carabidae). Syst. Entomol. 22: 345-362.

Nagel P. 2003: Carabidae: Paussinae. In Löbl I. \& Smetana A. (eds): Catalogue of Palaearctic Coleoptera. Vol. 1. Apollo Books, Stenstrup, pp. 19, 208-211.

NAGel P. 2009: Flanged bombardier beetles from Laos (Carabidae, Paussinae). Entomol. Basil. Coll. Frey 31: 101-113.

Oberprieler R.G. 1985: Paussidae. In: Scholtz C.H. \& Holm E. (eds): Insects of Southern Africa. Butterworth, Durban, pp. 196-198.

Vigna Taglianti A., Santarelli F., Di Giulio A. \& Oliverio M. 1998: Phylogenetic implications of larval morphology in the tribe Ozaenini (Coleoptera, Carabidae). In Ball G.E., Casale A. \& Vigna Taglianti A. (eds): Proceedings of the XX International Congress of Entomology (28 August, 1996, Florence, Italy). Museo Regionale di Scienze Naturali, Torino, pp. 273-296.

Wasmann E. 1918: Über Pleuropterus dohrni Rits. und lujae Wasm. und die Larve von Pleuropterus dohrni. Tijdschr. Entomol. 61: 76-87.

Xambeu V. 1892: Moeurs et metamorphoses d'insectes. Ann. Soc. Linn. Lyon 39: 135-194.

Zerche L. 1990: Book review. Beitr. Entomol. 40: 267-268.

Received June 15, 2010; revised and accepted September 6, 2010 